\title{
Avaliação de probióticos na dieta de frangos de corte criados em cama nova ou reutilizada ${ }^{1}$
}

\author{
Ana Beatriz Traldi ${ }^{2}$, Maria Cristina de Oliveira ${ }^{3}$, Karina Ferreira Duarte ${ }^{4}$, Vera Maria Barbosa \\ de Moraes $^{5}$ \\ 1 Parte da Dissertação de Mestrado em Zootecnia da primeira autora apresentada à FCAV-UNESP, Jaboticabal-SP. Projeto financiado pela \\ FAPESP e pela AGROCERES NUTRIÇÃO ANIMAL LTDA. \\ 2 Bolsista CAPES. Ms em Zootecnia FCAV-UNESP, Jaboticabal-SP. \\ ${ }^{3}$ Departamento de Zootecnia FESURV, Rio Verde - GO. \\ ${ }^{4}$ Pós-Graduação - Departamento de Zootecnia FCAV-UNESP, Jaboticabal - SP. \\ ${ }^{5}$ Departamento de Zootecnia FCAV-UNESP, Jaboticabal - SP.
}

RESUMO - Três experimentos foram conduzidos com o objetivo de avaliar o efeito da utilização de probióticos na dieta de frangos de corte sobre as características da cama reutilizada e das lesões de peito, joelho e coxim plantar. Foram utilizados em cada experimento 800 pintos machos de um dia, da linhagem comercial Ross, alojados em 20 boxes, em densidade populacional de 10 aves $/ \mathrm{m}^{2}$. O delineamento foi inteiramente casualizado e os tratamentos distribuídos em esquema fatorial $2 \times 2$ (cama nova ou reutilizada $\times$ rações com ou sem probiótico). O probiótico utilizado nas dietas foi composto por Bacillus subtilis e B. coagulans $\left(2 \times 10^{9}\right.$ e $1 \times 10^{7}$ ufc, respectivamente). Aos 42 dias de idade, quatro aves de cada boxe foram abatidas para análise das lesões de peito, joelho e coxim plantar. A cama de cada boxe foi amostrada para determinação dos teores de MS e nitrogênio, do potencial de volatilização de amônia e do pH. A cama reutilizada apresentou maior teor de MS, maiores valores de $\mathrm{pH}$ e potencial de volatilização de amônia e menor teor de nitrogênio. O probiótico usado nas rações resultou em maior potencial de volatilização de amônia. As lesões de coxim plantar e joelho foram maiores quando utilizada cama nova. As camas reutilizadas por dois, três e quatro ciclos causaram menores lesões de joelho e coxim plantar. O probiótico não promoveu efeito benéfico sobre a cama reutilizada.

Palavras-chave: Bacillus, qualidade da cama de frango, pH, potencial de volatilização de amônia

\section{Evaluation of probiotics in diets for broilers raised on new or reused litter}

ABSTRACT - Three experiments were conduced with the purpose of evaluating the effect of the addition of probiotics in the diet of broilers on the characteristics of reused litter and lesions of chest, knee and feet. Eight hundred male chicks, one day old, from Ross Commercial Breeding, were utilized in each experiment. The animals were housed in 20 pens in a populational density of $10 \mathrm{birds} / \mathrm{m}^{2}$. The experimental design was completely randomized and the treatments were organized in a $2 \times 2$ factorial arrangement (new or reused litter $\times$ diet with or without probiotic). The probiotic used in the feed was composed by Bacillus subtilis and B. coagulans $\left(2 \times 10^{9}\right.$ and $1 \times 10^{7}$ UFC respectively). When the animals were 42 days old, four birds from each box were slaughtered for determinations of DM and $\mathrm{N}$ contents and for measurements of potential for ammonia volatilization and $\mathrm{pH}$. The reused litter presented higher $\mathrm{DM}$ content, $\mathrm{pH}$ value and potential for ammonia volatilization, and lower $\mathrm{N}$ content. The probiotic used in the diet promoted a higher ammonia volatilization potential. The feet lesions were bigger in broilers raised on new litter. It was concluded that litter reused for two, three and four cycles caused less knee and feet lesions and that the use of probiotic in the diet did not promote any beneficial effect on the reused poultry litter.

Key Words: Bacillus, pH, poultry litter quality, potential for ammonia volatilization

\section{Introdução}

Estima-se que a produção anual da cama proveniente da criação de frangos de corte no Brasil seja em torno de 5 a 6 milhões de toneladas, portanto, a cama pode ser considerada o principal resíduo gerado na avicultura de corte, tendo sido reutilizada para diminuir os custos de produção e os impactos ambientais causados pelo seu descarte. A cama tem como principal função proporcionar maior conforto às aves, pois, quando criadas em galpões de piso compacto e duro podem apresentar lesões no coxim plantar, no joelho e no peito, bem como em outras áreas de menor valor comercial do corpo (Oliveira et al., 2002) 
$\mathrm{O}$ entendimento dos fatores que levam a lesões na carcaça de frangos de corte tem despertado o interesse de pesquisadores e produtores, especialmente porque podem acarretar prejuízos decorrentes da desvalorização das carcaças e da redução na velocidade de processamento industrial (Zavala, 1997).

O teor de umidade da cama pode ter grande influência sobre a incidência e a severidade das lesões na carcaça de frangos por ser um fator favorável ao desenvolvimento de bactérias que podem contaminar a pele e, conseqüentemente, a carcaça (Angelo et al., 1997). Em condições de umidade excessiva, a cama pode produzir amônia a partir do metabolismo microbiano sobre as excretas. A amônia produzida, ao se desprender, pode propiciar o aparecimento de lesões respiratórias e oculares nas aves. A reutilização da cama pode levar a altos níveis de amônia em galpões (60 a 100 ppm) até mesmo nos primeiros dias de criação do lote (Gonzáles \& Saldanha, 2001). Assim, é possível que os teores de umidade e nitrogênio aumentados com a excreção fecal das aves reintroduzidas no galpão aumentem o desenvolvimento bacteriano e a severidade de lesões de carcaça nesses animais.

Os probióticos podem melhorar o aproveitamento dos alimentos e reduzir a excreção de nutrientes. No entanto, poucos estudos têm sido realizados visando avaliar as características da cama reutilizada quando utilizados probióticos nas dietas. Além disso, pouco se conhece sobre a ação de probióticos sobre a cama, o que torna necessário avaliar o impacto gerado pela adição desse aditivo à dieta das aves sobre a cama, sobretudo quando reutilizada.

O objetivo neste trabalho foi avaliar o efeito do fornecimento de probiótico na dieta sobre as características da cama reutilizada por três ciclos subseqüentes e a incidência de lesões de peito, joelho e coxim plantar de frangos de corte.

\section{Material e Métodos}

Três experimentos foram conduzidos utilizando-se, em cada um, 800 pintos machos de um dia, da linhagem comercial Ross, alojados em 20 boxes (40 aves por boxe, em densidade populacional de 10 aves $/ \mathrm{m}^{2}$ ). Quatro boxes a mais, representando cada um dos tratamentos, foram designados a aves de reposição para que, em caso de descarte por refugagem ou morte, se mantivesse constante a densidade populacional durante todo o ciclo de criação.

O delineamento experimental adotado foi o inteiramente casualizado, com os tratamentos distribuídos em esquema fatorial $2 \times 2$, composto de dois tipos de cama (nova e reutilizada) e dois tipos de dieta (com e sem probiótico). As dietas iniciais e de crescimento eram fareladas, isoenergéticas e isoprotéicas e foram formuladas com base na composição dos nutrientes e nas exigências nutricionais descritas por Rostagno et al. (2000).

O probiótico utilizado era composto de Bacillus subtilis $\left(2 \times 10^{9}\right.$ ufc) e Bacillus coagulans $\left(1 \times 10^{7}\right.$ ufc $)$ e sua inclusão na dieta foi na proporção de $0,06 \%$, conforme recomendação do fabricante. Como cama, utilizou-se maravalha ( $10 \mathrm{~cm}$ de altura) nas quantidades padronizadas de $24,71,105$ e $130 \mathrm{~kg} /$ boxe para cama nova, de $2 \stackrel{\circ}{\circ}, 3-$ o $4 \stackrel{0}{\circ}$ ciclos, respectivamente.

Durante o período de criação, adotou-se programa de luz contínuo (24 horas de luz por dia)e, para melhorar a ambiência dentro do galpão, além do manejo de cortinas, utilizaram-se a partir dos 21 dias de idade, ventiladores durante as horas mais quentes do dia. $\mathrm{O}$ monitoramento das temperaturas máximas e mínimas dentro do galpão foi feito por meio de termômetro de mercúrio colocado à altura das aves.

A cada ciclo, houve intervalo de sete dias e, nesse período, a cama que seria reutilizada não recebeu qualquer tratamento para desinfecção; apenas espalhou-se uma camada de aproximadamente 1,0 cm de maravalha.

O manejo diário de limpeza dos bebedouros e fornecimento da alimentação foi realizado conforme uma seqüência de entrada nos boxes: cama nova sem probiótico; cama reutilizada sem probiótico; cama reutilizada com probiótico e cama nova com probiótico.

Ao final dos 42 dias, quatro aves de cada boxe foram abatidas por deslocamento cervical e sangria e posteriormente avaliadas por dois examinadores para atribuição dos escores de lesões de peito, segundo metodologia descrita por Angelo et al. (1997), e escores de joelho e coxim plantar, conforme técnica descrita por Mc Ward \& Taylor (2000).

As amostras de cama foram coletadas em seis pontos diferentes de cada boxe, evitando-se as áreas próximas ao comedouro e ao bebedouro. Foram determinados os teores de MS e nitrogênio (Silva, 2002), o pH (Benabdeljelil \& Ayachi, 1996) e o potencial de volatilização de amônia (Oliveira et al., 2004)

A análise estatística dos dados foi realizada por meio do programa Sistema de Análises Estatísticas e Genéticas SAEG (UFV, 2002) e, no caso de diferenças significativas, as médias foram comparadas pelos testes Tukey (MS, N, pH e potencial de volatilização de amônia) e WILCOXON (lesões de peito, joelho e coxim plantar).

\section{Resultados e Discussão}

As temperaturas máximas e mínimas registradas (em graus Celsius) no $1 \stackrel{\circ}{\circ}, 2 \underline{o}$ e $3 \stackrel{o}{\circ}$ ciclos foram 31,3 e 20,4; 30,7 e 18,$3 ; 25,4$ e 14,1 , respectivamente. Os teores de MS e N, o 
Tabela 1 - Composição das dietas utilizadas nas fases inicial e de crescimento

Table 1 - Percentage composition (as fed basis) and calculated nutritional contents of starter and grower diets

\begin{tabular}{lcc}
\hline $\begin{array}{l}\text { Ingrediente }(\%) \\
\text { Ingredient (\%) }\end{array}$ & $\begin{array}{c}\text { Inicial (1 a 21 dias) } \\
\text { Starter (1 to 21 days) }\end{array}$ & $\begin{array}{c}\text { Crescimento (22 a } 42 \text { dias) } \\
\text { Grower (22 to } 42 \text { days) }\end{array}$ \\
\hline Milho (Corn) & 55,831 & 61,510 \\
Farelo de soja (Soybean meal) & 36,560 & 31,000 \\
Óleo de soja (Soybean oil) & 3,450 & 3,670 \\
Calcário (Limestone) & 0,980 & 0,930 \\
Fosfato bicálcico (Dicalcium phosphate) & 1,820 & 1,620 \\
Sal (Salt) & 0,450 & 0,382 \\
Mistura de vitaminas e minerais1 (Vitamin and mineral mix) & 0,500 & 0,300 \\
DL-metionina (99\%) (DL-methionine) & 0,000 & 0,120 \\
L-lisina (78\%) (L-lysine) & 0,137 & 0,330 \\
Antioxidante (Antioxidant) & 0,050 & 0,050 \\
Inerte/Probiótico (Inert/Probiotic) & 0,060 & 0,060 \\
Total & 100 & 100
\end{tabular}

Composição nutricional calculada

Calculated nutritional composition

$\mathrm{PB}(C P)(\%)$

$\mathrm{EM}(M E)(\mathrm{kcal} / \mathrm{kg})$

$\mathrm{Ca}(\%)$

P disponível (\%) (Available P)

$\mathrm{Na}(\%)$

$\mathrm{K}(\%)$

Lisina $(\%)$ (Lysine)

Metionina (\%) (Methionine)

Metionina + Cistina (\%) (Methionine + Cystine)

Arginina (\%) (Arginine)

Treonina (\%) (Threonine)

Triptofano (\%) (Tryptophan)

21,400
3000
0,960
0,450
0,222
0,825
1,263
0,530
1,156
1,441
0,849
0,245

\section{9,300}

3100

0,874

0,406

0,192

0,739

1,156

0,560

1,074

1,278

0,764

0,216

\footnotetext{
1 Premix Aves Agroceres Nutrição Animal Ltda (Poultry Premix Agroceres Nutrição Animal Ltda). Composição por kg do produto (Composition perkg of product): fase inicial (starter phase): ácido fólico (folic acid) - $140 \mathrm{mg}$; ácido pantotênico (pantothenic acid) - $1.600 \mathrm{mg}$; antifúngico (antifungic) - $3.000 \mathrm{mg}$; antioxidante (antioxidant) $990 \mathrm{mg}$; biotina (biotin) - $12 \mathrm{mg}$; Cu - $1.200 \mathrm{mg}$; colina (choline) - $65 \mathrm{mg} ; \mathrm{Fe}-10.000 \mathrm{mg} ; \mathrm{I}-240 \mathrm{mg} ; \mathrm{Mn}$ - $12.000 \mathrm{mg}$; metionina (methionine) - $353.430 \mathrm{mg}$; niacina (niacin) - $3.000 \mathrm{mg}$; piridoxina (piridoxine) - $400 \mathrm{mg}$; riboflavina (riboflavin) - $800 \mathrm{mg}$; Se (selenium) - $80 \mathrm{mg}$; tiamina (thiamin) - $200 \mathrm{mg}$; vit. A - $1.600 .000 \mathrm{Ul} / \mathrm{kg}$; vit. B12 - $2.000 \mathrm{mcg}$; vit. D3 - $400.000 \mathrm{Ul} / \mathrm{kg}$; vit. E - $3.000 \mathrm{mg}$; vit. K3 - $400 \mathrm{mg}$; Zn - 12.000 mg. Fase de crescimento (growing fase): ácido fólico (folic acid) - $100 \mathrm{mg}$; ácido pantotênico (pantothenic acid) - 1.333,6 mg; antioxidante (antioxidant) - $990 \mathrm{mg}$; biotina (biotin) - 6.6 mg; Cu - 2.000 mg; colina (choline) 50 mg; Fe - 16.670 mg; I - 400 mg; Mn - 20.004 mg; metionina (methionine) - 243.000 mg; niacina (niacin) - 2.000 mg; piridoxina (piridoxine) - 200 mg; riboflavina (riboflavin) - $665 \mathrm{mg}$; Se - 66,7 mg; tiamina (thiamin) - $133 \mathrm{mg}$; vit. A - $1.300 .000 \mathrm{UI} / \mathrm{kg}$; vit. B12 - $1667 \mathrm{mcg}$; vit. D3 - $400.000 \mathrm{UI} / \mathrm{kg}$; vit. E - 2167 mg; vit. K3 - $333 \mathrm{mg}$; Zn - $20.003 \mathrm{mg}$.
}

pH e o potencial de volatilização de amônia para as camas de 2oㅡ, 3o e 4o ciclos são descritos na Tabela 2.

Em todos os ciclos de criação, a cama nova, em comparação à cama reutilizada, apresentou menor teor de MS, o que pode ser atribuído à sua menor granulometria, o que aumenta a área de superfície específica das partículas e favorece a perda de água. Resultados semelhantes foram encontrados por Santos et al. (2000), que afirmaram que camas de menor granulometria (moídas) apresentam menos umidade se comparadas às de maior granulometria.

$\mathrm{O}$ pH e o potencial de volatilização de amônia diferiram significativamente entre os tipos de cama, sendo maiores para a cama reutilizada, o que era esperado, visto que um dos fatores que mais determinam a menor ou maior volatilização da amônia é o $\mathrm{pH}$. Valores de $\mathrm{pH}$ superiores a 7,0 normalmente estimulam a proliferação bacteriana na cama e aumentam a produção de amônia.

O potencial de volatilização de amônia foi maior com o uso de probiótico, provavelmente porque o probiótico promove aumento da absorção de nitrogênio pelas aves, mas não sua retenção, resultando, portanto, em maior excreção de ácido úrico, convertido em amônia na cama de frango. Weaver Jr. \& Meijerhof (1991) atribuíram a volatilização de amônia dentro do galpão à degradação de compostos nitrogenados, principalmente o ácido úrico presente nas excretas, e verificaram que o aumento da volatilização está relacionado à elevação do nível de ácido úrico.

Nos dois últimos ciclos, o teor de nitrogênio da cama diminuiu com o uso de probiótico, o que significa que a maior excreção desse nutriente pelas aves ocorreu na forma de ácido úrico, que foi convertido em amônia e volatilizado, confirmando, assim, o maior potencial de volatilização no tratamento com probiótico. Esse resultado talvez possa ser explicado pelo nível de proteína da dieta (suficiente) e pelo uso do probiótico, que, ao melhorar o aproveitamento do nitrogênio da dieta, favoreceu sua absorção, mas não sua retenção, promovendo maior excreção de ácido úrico. 
Tabela 2 - Características da cama de $2 \underline{0}, 3 ㅇ$ e 40 ciclos utilizada na criação de frangos de corte alimentados com dietas contendo probiótico Table 2 - Characteristics of litter from $2^{\text {nd }}, 3^{\text {rd }}$ and $4^{\text {th }}$ utilization cycles, from broiler fed diets containing probiotic

\begin{tabular}{|c|c|c|c|c|c|}
\hline \multirow{3}{*}{$\begin{array}{l}\text { Característica } \\
\text { Characteristic }\end{array}$} & \multirow[t]{2}{*}{$\begin{array}{l}\text { Cama } \\
\text { Litter }\end{array}$} & \multicolumn{2}{|c|}{$\begin{array}{c}\text { Probiótico } \\
\text { Probiotic }\end{array}$} & \multirow[b]{2}{*}{$\begin{array}{l}\text { Média } \\
\text { Mean }\end{array}$} & \multirow[t]{2}{*}{$\mathrm{CV}(\%)$} \\
\hline & & $\begin{array}{c}\text { Sem } \\
\text { Without }\end{array}$ & $\begin{array}{l}\text { Com } \\
\text { With }\end{array}$ & & \\
\hline & \multicolumn{4}{|c|}{$2^{\circ}$ ciclo } & \\
\hline $\begin{array}{l}\text { MS (\%) } \\
D M\end{array}$ & $\begin{array}{l}\text { Nova (Fresh) } \\
\text { Reutilizada (Reused) } \\
\text { Média (Mean) }\end{array}$ & $\begin{array}{l}76 \\
74 \\
78\end{array}$ & $\begin{array}{l}79 \\
76 \\
81\end{array}$ & $\begin{array}{l}75^{\mathrm{B}} \\
80^{\mathrm{A}}\end{array}$ & 3,6 \\
\hline $\mathrm{pH}$ & $\begin{array}{l}\text { Nova (Fresh) } \\
\text { Reutilizada (Reused) } \\
\text { Média (Mean) }\end{array}$ & $\begin{array}{l}8,1 \\
8,6 \\
8,4\end{array}$ & $\begin{array}{l}8,4 \\
8,8 \\
8,6\end{array}$ & $\begin{array}{l}8,2^{\mathrm{B}} \\
8,7^{\mathrm{A}}\end{array}$ & 3,2 \\
\hline $\begin{array}{l}\text { Potencial de volatilização de amônia }(\mathrm{ppm})^{1} \\
\text { Potential for ammonia volatilization }\end{array}$ & $\begin{array}{l}\text { Nova (Fresh) } \\
\text { Reutilizada (Reused) } \\
\text { Média (Mean) }\end{array}$ & $\begin{array}{r}13,4 \\
34,5 \\
24,0^{\mathrm{b}}\end{array}$ & $\begin{array}{r}22,0 \\
54,1 \\
38,0^{\mathrm{a}}\end{array}$ & $\begin{array}{l}17,7^{\mathrm{B}} \\
44,3^{\mathrm{A}}\end{array}$ & $16,5^{1}$ \\
\hline \multirow[t]{2}{*}{ N (\%) } & $\begin{array}{l}\text { Nova (Fresh) } \\
\text { Reutilizada (Reused) } \\
\text { Média (Mean) }\end{array}$ & $\begin{array}{l}3,2 \\
3,0 \\
3,1\end{array}$ & $\begin{array}{l}3,0 \\
2,9 \\
3,0\end{array}$ & $\begin{array}{l}3,1 \\
3,0\end{array}$ & 7,9 \\
\hline & \multicolumn{3}{|c|}{3 o ciclo } & & \\
\hline $\begin{array}{l}\mathrm{MS}(\%) \\
D M\end{array}$ & $\begin{array}{l}\text { Nova (Fresh) } \\
\text { Reutilizada (Reused) } \\
\text { Média (Mean) }\end{array}$ & $\begin{array}{l}74 \\
79 \\
76\end{array}$ & $\begin{array}{l}73 \\
76 \\
74\end{array}$ & $\begin{array}{l}74^{\mathrm{B}} \\
76^{\mathrm{A}}\end{array}$ & 3,4 \\
\hline $\mathrm{pH}$ & $\begin{array}{l}\text { Nova (Fresh) } \\
\text { Reutilizada (Reused) } \\
\text { Média (Mean) }\end{array}$ & $\begin{array}{l}8,1 \\
8,4 \\
8,3\end{array}$ & $\begin{array}{l}8,3 \\
8,6 \\
8,5\end{array}$ & $\begin{array}{l}8,2^{\mathrm{B}} \\
8,5^{\mathrm{A}}\end{array}$ & 2,6 \\
\hline $\begin{array}{l}\text { Potencial de volatilização de amônia }(\mathrm{ppm})^{1} \\
\text { Ammonia volatilized potential }\end{array}$ & $\begin{array}{l}\text { Nova (Fresh) } \\
\text { Reutilizada (Reused) } \\
\text { Média (Mean) }\end{array}$ & $\begin{array}{r}15,6 \\
30,1 \\
22,9^{b}\end{array}$ & $\begin{array}{r}32,3 \\
57,1 \\
44,7^{\mathrm{a}}\end{array}$ & $\begin{array}{l}24,0^{\mathrm{B}} \\
43,6^{\mathrm{A}}\end{array}$ & $9,8^{1}$ \\
\hline N (\%) & $\begin{array}{l}\text { Nova (Fresh) } \\
\text { Reutilizada (Reused) } \\
\text { Média (Mean) }\end{array}$ & $\begin{array}{l}3,2 \\
3,0 \\
3,1^{\mathrm{a}}\end{array}$ & $\begin{array}{r}3,0 \\
2,7 \\
2,8^{b}\end{array}$ & $\begin{array}{l}3,1^{\mathrm{A}} \\
2,9^{\mathrm{B}}\end{array}$ & 5,5 \\
\hline $\begin{array}{l}\text { MS (\%) } \\
D M\end{array}$ & $\begin{array}{l}\text { Nova (Fresh) } \\
\text { Reutilizada (Reused) } \\
\text { Média (Mean) }\end{array}$ & $\begin{array}{l}74 \\
78 \\
76\end{array}$ & $\begin{array}{r}75 \\
76 \\
75,5\end{array}$ & $\begin{array}{l}74,5^{\mathrm{B}} \\
77,0^{\mathrm{A}}\end{array}$ & 6,9 \\
\hline $\mathrm{pH}$ & $\begin{array}{l}\text { Nova (Fresh) } \\
\text { Reutilizada (Reused) } \\
\text { Média (Mean) }\end{array}$ & $\begin{array}{l}9,0 \\
9,4 \\
9,2\end{array}$ & $\begin{array}{l}9,2 \\
9,0 \\
9,1\end{array}$ & $\begin{array}{l}9,1^{\mathrm{B}} \\
9,2^{\mathrm{A}}\end{array}$ & 9,7 \\
\hline $\begin{array}{l}\text { Potencial de volatilização de amônia }(\mathrm{ppm})^{1} \\
\text { Potential for ammonia volatilization }\end{array}$ & $\begin{array}{l}\text { Nova (Fresh) } \\
\text { Reutilizada (Reused) } \\
\text { Média (Mean) }\end{array}$ & $\begin{array}{r}9,2 \\
21,6 \\
15,4^{\mathrm{b}}\end{array}$ & $\begin{array}{r}20,1 \\
20,7 \\
20,4^{\mathrm{a}}\end{array}$ & $\begin{array}{l}14,6^{\mathrm{B}} \\
21,1^{\mathrm{A}}\end{array}$ & $38,6^{1}$ \\
\hline \multirow[t]{2}{*}{ N (\%) } & $\begin{array}{l}\text { Nova (Fresh) } \\
\text { Reutilizada (Reused) } \\
\text { Média (Mean) }\end{array}$ & $\begin{array}{r}3,2 \\
3,0 \\
3,1^{\mathrm{a}}\end{array}$ & $\begin{array}{r}3,0 \\
2,7 \\
2,9^{b}\end{array}$ & $\begin{array}{l}3,0^{\mathrm{A}} \\
2,9^{\mathrm{B}}\end{array}$ & 5,5 \\
\hline & \multicolumn{4}{|c|}{ 4o ciclo } & \\
\hline $\begin{array}{l}\text { MS (\%) } \\
D M\end{array}$ & $\begin{array}{l}\text { Nova (Fresh) } \\
\text { Reutilizada (Reused) } \\
\text { Média (Mean) }\end{array}$ & $\begin{array}{l}74 \\
78 \\
76\end{array}$ & $\begin{array}{r}75 \\
76 \\
75,5\end{array}$ & $\begin{array}{r}74,5 \mathrm{~B} \\
77,0 \mathrm{~A} \\
6,9\end{array}$ & \\
\hline $\mathrm{pH}$ & $\begin{array}{l}\text { Nova (Fresh) } \\
\text { Reutilizada (Reused) } \\
\text { Média (Mean) }\end{array}$ & $\begin{array}{l}9,0 \\
9,4 \\
9,2\end{array}$ & $\begin{array}{l}9,2 \\
9,0 \\
9,1\end{array}$ & $\begin{array}{l}9,1 \mathrm{~B} \\
9,2 \mathrm{~A}\end{array}$ & 9,7 \\
\hline $\begin{array}{l}\text { Potencial de volatilização de amônia }(\mathrm{ppm})^{1} \\
\text { Potential for ammonia volatilization }\end{array}$ & $\begin{array}{l}\text { Nova (Fresh) } \\
\text { Reutilizada (Reused) } \\
\text { Média (Mean) }\end{array}$ & $\begin{array}{r}9,2 \\
21,6 \\
15,4 \mathrm{~b}\end{array}$ & $\begin{array}{r}20,1 \\
20,7 \\
20,4 \mathrm{a}\end{array}$ & $\begin{array}{l}14,6 \mathrm{~B} \\
21,1 \mathrm{~A}\end{array}$ & 38,61 \\
\hline N (\%) & $\begin{array}{l}\text { Nova (Fresh) } \\
\text { Reutilizada (Reused) } \\
\text { Média (Mean) }\end{array}$ & $\begin{array}{r}3,2 \\
3,0 \\
3,1 \mathrm{a}\end{array}$ & $\begin{array}{r}3,0 \\
2,7 \\
2,9 b\end{array}$ & $\begin{array}{l}3,0 \mathrm{~A} \\
2,9 \mathrm{~B}\end{array}$ & 5,5 \\
\hline
\end{tabular}

\footnotetext{
${ }^{1}$ Coeficiente de variação obtido com médias transformadas $\left(\log _{10} X\right)$. Médias seguidas de letras diferentes na linha (minúsculas) e na coluna (maiúsculas) diferem pelo teste
} Tukey $(\mathrm{P}<0,05)$ (Coeficient of variation obtained with transformed means $\left(\log _{10} X\right)$. Means followed by different letters in a row (small) and in the column (capitalletters), differ by Tukey test [P<0.05]). 
Tabela 3 - Escore de lesões de coxim plantar e joelho de frangos de corte alimentados com dietas contendo probiótico e criados em cama reutilizada

Table 3 - Foot pad and hock lesion scores in broilers fed diets with probiotic and raised on second flock litter

\begin{tabular}{|c|c|c|c|c|c|}
\hline \multirow[b]{2}{*}{$\begin{array}{l}\text { Parâmetro } \\
\text { Parameter }\end{array}$} & \multirow[t]{2}{*}{$\begin{array}{l}\text { Cama } \\
\text { Litter }\end{array}$} & \multicolumn{2}{|c|}{$\begin{array}{c}\text { Probiótico } \\
\text { Probiotic }\end{array}$} & \multirow[b]{2}{*}{$\begin{array}{c}\text { Média } \\
\text { Mean }\end{array}$} & \multirow[t]{2}{*}{$\mathrm{CV}(\%)$} \\
\hline & & $\begin{array}{c}\text { Sem } \\
\text { Without }\end{array}$ & $\begin{array}{l}\text { Com } \\
\text { With }\end{array}$ & & \\
\hline \multicolumn{6}{|c|}{ 2o ciclo } \\
\hline $\begin{array}{l}\text { Coxim plantar } \\
\text { Foot pad }\end{array}$ & $\begin{array}{l}\text { Nova (Fresh) } \\
\text { Reutilizada (Reused) } \\
\text { Média (Mean) }\end{array}$ & $\begin{array}{l}2,2 \\
0,9 \\
1,6\end{array}$ & $\begin{array}{l}1,2 \\
1,0 \\
1,1\end{array}$ & $\begin{array}{l}1,7^{\mathrm{a}} \\
1,0^{\mathrm{b}}\end{array}$ & 22,1 \\
\hline $\begin{array}{l}\text { Joelho } \\
\text { Hock }\end{array}$ & $\begin{array}{l}\text { Nova (Fresh) } \\
\text { Reutilizada (Reused) } \\
\text { Média (Mean) }\end{array}$ & $\begin{array}{l}1,1 \\
0,2 \\
0,6\end{array}$ & $\begin{array}{l}0,7 \\
0,6 \\
0,6\end{array}$ & $\begin{array}{l}0,9 \\
0,4\end{array}$ & 16,9 \\
\hline \multicolumn{6}{|c|}{3 o ciclo } \\
\hline $\begin{array}{l}\text { Coxim plantar } \\
\text { Foot pad }\end{array}$ & $\begin{array}{l}\text { Nova (Fresh) } \\
\text { Reutilizada (Reused) } \\
\text { Média (Mean) }\end{array}$ & $\begin{array}{l}1,4 \\
1,1 \\
1,3\end{array}$ & $\begin{array}{l}1,3 \\
1,2 \\
1,3\end{array}$ & $\begin{array}{l}1,3^{\mathrm{a}} \\
1,1^{\mathrm{b}}\end{array}$ & 17,6 \\
\hline $\begin{array}{l}\text { Joelho } \\
\text { Hock }\end{array}$ & $\begin{array}{l}\text { Nova (Fresh) } \\
\text { Reutilizada (Reused) } \\
\text { Média (Mean) }\end{array}$ & $\begin{array}{l}1,1 \\
1,0 \\
1,0\end{array}$ & $\begin{array}{l}1,0 \\
1,0 \\
1,0\end{array}$ & $\begin{array}{l}1,1 \\
1,0\end{array}$ & 9,7 \\
\hline \multicolumn{6}{|c|}{ 4o ciclo } \\
\hline $\begin{array}{l}\text { Coxim plantar } \\
\text { Foot pad }\end{array}$ & $\begin{array}{l}\text { Nova (Fresh) } \\
\text { Reutilizada (Reused) } \\
\text { Média (Mean) }\end{array}$ & $\begin{array}{l}1,7 \\
1,1 \\
1,4\end{array}$ & $\begin{array}{l}1,3 \\
1,2 \\
1,2\end{array}$ & $\begin{array}{l}1,5^{\mathrm{a}} \\
1,2^{\mathrm{b}}\end{array}$ & 13,1 \\
\hline $\begin{array}{l}\text { Joelho } \\
\text { Hock }\end{array}$ & $\begin{array}{l}\text { Nova (Fresh) } \\
\text { Reutilizada (Reused) } \\
\text { Média (Mean) }\end{array}$ & $\begin{array}{l}1,2 \\
1,0 \\
1,1\end{array}$ & $\begin{array}{l}1,1 \\
1,0 \\
1,0\end{array}$ & $\begin{array}{l}1,2^{\mathrm{a}} \\
1,0^{\mathrm{b}}\end{array}$ & 17,5 \\
\hline
\end{tabular}

${ }^{1}$ Coeficiente de variação obtido com médias transformadas $(\sqrt{\mathrm{x}+1})$.

Médias seguidas de letras diferentes na coluna diferem entre si pelo teste Wilcoxon.

1 Coefficient of variation obtained with transformed means $(\sqrt{\mathrm{x}+1})$.

Means followed by different letter differ by Wilcoxon test).

Não foram encontradas lesões de peito em nenhum dos ciclos (Tabela 3), o que está de acordo com os resultados obtidos por Willis et al. (1997), que, ao avaliarem lesões de carcaça de aves criadas sobre diferentes tipos de cama, não encontraram diferença significativa para lesões de peito.

O uso de probiótico não afetou significativamente os escores de lesões no joelho e coxim plantar. A reutilização da cama, no entanto, afetou significativamente a incidência de lesões no coxim plantar das aves em todos os ciclos de criação. Os escores de joelho foram influenciados por esse fator apenas no quarto ciclo. Os escores de lesões de coxim plantar e joelho foram maiores nos frangos criados sobre cama nova, o que pode ser atribuído ao maior teor de umidade da cama nova. Embora não se tenha avaliado a granulometria da cama neste estudo, foi possível verificar visualmente que, à medida que a cama era reutilizada, suas partículas diminuíam, o que pode ter favorecido a menor incidência de lesões de joelho e coxim plantar nas aves. Estes resultados corroboram os obtidos por Wang et al. (1993), que compararam a incidência de lesões no coxim plantar de aves criadas sobre camas secas e úmidas e observaram que $38 \%$ das aves criadas sobre cama seca apresentaram lesões, enquanto, em cama úmida, a incidência foi de $92 \%$.

\section{Conclusões}

O probiótico não promoveu efeito benéfico sobre a cama reutilizada. As camas reutilizadas por dois, três e quatro ciclos causaram menos lesões de joelho e coxim plantar em comparação à cama nova.

\section{Agradecimento}

À Agroceres Nutrição Animal LTDA, pela concessão das aves e do premix; à FAPESP, pelo auxílio à pesquisa; $\mathrm{e}$ à CAPES, pela bolsa de estudos.

\section{Literatura Citada}

ÂNGELO, J.A.; GONZÁLES, E.; KONDO, N. et al. Material de cama: qualidade, quantidade e efeito sobre o desempenho de frangos de 
corte. Revista Brasileira de Zootecnia, v.26, n.1, p.121-130, 1997

BENABDELJELIL, K.; AYACHI, A. Evaluation of alternative litter materials for poultry. Journal of Applied Poultry Research, v.5, p.203-209, 1996.

GONZÁLES, E.; SALDANHA, E.S.P.B. Os primeiros dias de vida do frango e a produtividade futura. In: CONGRESSO BRASILEIRO DE ZOOTECNIA, 11., 2001, Goiânia. Palestras... Goiânia: 2001. p.312-313.

Mc WARD, G.W.; TAYLOR, D.R. Acidified clay litter amendment. Journal of Applied Poultry Research, v.9, n.4, p.518-529, 2000.

OLIVEIRA, M.C.; GOURLART, R.B.; SILVA, J.C.N. Efeito de duas densidades e dois tipos de cama sobre a umidade da cama e a incidência de lesões na carcaça de frangos de corte. Ciência Animal Brasileira, v.3, n.2, p.7-12, 2002.

OLIVEIRA, M.C.; FERREIRA, H.A.; CANCHERINI, L.C. Efeito do uso de condicionadores químicos sobre a qualidade da cama de frango. Arquivo Brasileiro de Medicina Veterinária e Zootecnia, v.54, n.4, p.536-541, 2004.

ROSTAGNO, H.S.; ALBINO, L.F.T.; DONZELE, J.L. et al. Composição de alimentos e exigências nutricionais de aves e suínos: tabelas brasileiras. Viçosa, MG: Universidade Federal de Viçosa, 2000. 59p.

UNIVERSIDADE FEDERAL DE VIÇOSA - UFV. Sistema de Análises Estatísticas e Genéticas - SAEG. versão 9,0. Viçosa, MG: Fundação Arthur Bernardes, 2002. (CD-ROM)
SANTOS, E.C.; TEIXEIRA, A.S.; TORRES, D.M. et al. Avaliação das propriedades de quatro materiais e duas granulometrias de cama sobre o desempenho de frangos de corte: In: REUNIÃO ANUAL DA SOCIEDADE BRASILEIRA DE ZOOTECNIA, 2000, Viçosa, MG. Anais... Viçosa, MG: Sociedade Brasileira de Zootecnia, 2000. p.37.

SILVA, D.J.; QUEIROZ, A.C. Análise de alimentos: métodos químicos e biológicos. 3.ed. Viçosa, MG: Editora UFV, 2002. $235 \mathrm{p}$.

WANG, G.; EKSTRAND, C.; SVEDBERG, J. Wet litter and perches a risk factors for the development of foot pad dermatitis in floor-housed hens. British Poutry Science, v.39, n.2, p.191-197, 1993.

WEAVER, W.D.; MEIJERHOF, R. The effect of different levels of relative humidity and air movement on litter conditions, ammonia levels, growth and carcass quality for broiler chickens. Poultry Science, v.70, p.746-755, 1991.

WILLIS, W.L.; MURRAY, C.; TALBOTT, C. Evaluation of leaves litter material. Poultry Science, v.76, n.8, p.1138-1140, 1997.

ZAVALA, G. Manejo de problemas locomotores en reproductoras pesadas. Avicultura Profesional, v.15, n.4, p.26-28, 1997.

Recebido: $12 / 12 / 05$ Aprovado: 07/11/06 